\title{
Endoplasmic reticulum stress induces liver cells apoptosis after brain death by suppressing the phosphorylation of protein phosphatase $2 \mathrm{~A}$
}

\author{
JIA'NAN LAN ${ }^{1}$, ZIBIAO ZHONG $^{1}$, YANFENG WANG $^{1}$, YAN XIONG $^{1}$ and QIFA YE ${ }^{1,2}$ \\ ${ }^{1}$ Zhongnan Hospital of Wuhan University, Institute of Hepatobiliary Diseases of Wuhan University, Transplant Center of \\ Wuhan University, Hubei Key Laboratory of Medical Technology on Transplantation, Wuhan, Hubei 430071; \\ ${ }^{2}$ The Third Xiangya Hospital of Central South University, Research Center of National Health Ministry \\ on Transplantation Medicine Engineering and Technology, Changsha, Hunan 410013, P.R. China
}

Received September 28, 2016; Accepted August 12, 2019

DOI: $10.3892 / \mathrm{mmr} .2019 .10874$

\begin{abstract}
The present study aimed to investigate whether brain death (BD) induces the activation of endoplasmic reticulum stress (ERS) and protein phosphatase 2A (PP2A), and reveal the possible association with BD-induced liver cell apoptosis. A total of 30 healthy adult male Sprague-Dawley rats were randomized into three groups: Sham-operated group (S), BD group and 4-phenylbutyric acid group (BD + 4-PBA), with 10 rats in each group. All rats were anesthetized. The model of BD was established by inflating a balloon catheter that was placed into the extradural space after anesthesia. 4-PBA was administered via an intraperitoneal injection when the BD model was established. Anesthesia of the $\mathrm{S}$ group of rats was maintained for $6 \mathrm{~h}$. Liver tissues were harvested after $6 \mathrm{~h}$ of BD. HE staining was used to evaluate the damage of liver. Terminal deoxynucleotidyl transferase-mediated 2'-deoxyuridine 5'-triphosphate nick-end labeling staining was used to observe the apoptosis of liver cells. Activation of ERS and PP2A was examined by western blotting and immunohistochemical staining. We reported that the apoptosis of liver cells after BD was significantly promoted than in the $\mathrm{S}$ group. Activation of
\end{abstract}

Correspondence to: Professor Qifa Ye or Dr Yan Xiong, Zhongnan Hospital of Wuhan University, Institute of Hepatobiliary Diseases of Wuhan University, Transplant Center of Wuhan University, Hubei Key Laboratory of Medical Technology on Transplantation, 169 Donghu Road, Wuhan, Hubei 430071, P.R. China

E-mail: yqf_china@163.com

E-mail: 278158821@qq.com

Abbreviations: $\mathrm{BD}$, brain death; DBD, donation after brain death; 4-PBA, phenylbutyric acid; ERS, endoplasmic reticulum stress; PP2A, protein phosphatase 2A; Grp78, glucose-regulated protein 78; PERK, protein kinase RNA-like ER kinase; IRE1 $\alpha$, inositol-requiring enzyme $1 \alpha$; ATF6, activating transcription factor 6

Key words: brain death, liver, intracranial hypertension, endoplasmic reticulum stress, protein phosphatase $2 \mathrm{~A}$
ERS and PP2A was induced in the BD group when compared with $\mathrm{S}$ group. Phosphorylation of PP2A was suppressed in BD group. Application of 4-PBA decreased the activation of ERS and apoptosis rate compared with the BD group. In addition, activation of PP2A in the BD + 4-PBA group was decreased due to the reduction of $\mathrm{PP} 2 \mathrm{~A}$ phosphorylation compared with the BD group, but the levels were higher than in the $\mathrm{S}$ group. $(\mathrm{P}<0.05)$. In summary, our results indicated that BD induced ERS, then activated PP2A by suppressing the phosphorylation of PP2A, resulting in the apoptosis of liver cells.

\section{Introduction}

Liver transplantation (LT) is the most effective treatment for end-stage liver diseases; however, donor shortage has confined the application of LT (1). Donation after brain death (DBD) may possibly overcome the severe imbalance between organ transplant demand and recipients. On the contrary, BD is a complex pathophysiologic process which may affects donor organs. Compared with living donors, there is an approximate graft survival rate in adult liver transplantation while in pediatric liver transplantation the graft survival rate of DBD donor was significantly lower than a living donor or split-liver transplantation (2). It has been demonstrated that the primary factor of BD-induced liver damage was the Cushing reaction, and the subsequent severe changes in the hemodynamic and oxygenation state (3). Previously, it was indicated that BD was associated with the endoplasmic reticulum (ER) $(4,5)$. The ER is one of the most important organelles involved in protein synthesis and folding (6). While many adverse factors can obstruct the physiological function of the ER, leading to the damage this organelle, ER stress (ERS) can occur through protein kinase RNA-like ER kinase (PERK), inositol-requiring enzyme $1 \alpha(\mathrm{IRE} 1 \alpha)$ and activating transcription factor 6 (ATF6) pathways, which would finally induce apoptosis $(7,8)$. Protein phosphatase 2A (PP2A) is a major serine/threonine phosphatase in cells. It plays critical roles in many physiological processes such as cell proliferation, migration, cell cycle control and death (9). Currently, several studies have revealed that ERS could induce activation of PP2A resulting in apoptosis (10-12). 
The present study aimed to investigate the relationship between ERS and PP2A in liver cell damage after BD.

\section{Materials and methods}

Animals and grouping. Thirty male adult Sprague-Dawley rats, weighing $300 \pm 20 \mathrm{~g}, \sim 8$ weeks of age were obtained from the Centers for Disease Control and Prevention of Wuhan (Wuhan, China), and were maintained in the Animal Experimental Center of Zhongnan Hospital, Wuhan University (Wuhan China). Prior to the experiments, standard chow and water were given to the rats ad libitum, and they were housed at $20-25^{\circ} \mathrm{C}$ and $50-70 \%$ humidity with a $12 \mathrm{~h}$ light/dark cycle. All the rats were randomized into three groups equally: Sham-operation group (S group), BD group, and 4-phenylbutyric acid group (4-PBA group), with 10 rats in each group. All animals were fed in the Animal Experiment Center of Zhongnan Hospital of Wuhan University 7 days before the experimental operation. All experiment operations were performed in accordance with the Experimental Animal Regulations of the People's Republic of China and the Guide for the Care and Use of Laboratory Animals (13). Prior to the establishment of animal model all animals were fasted overnight but had free access to water.

Establishment of animal model and specimens harvesting. The BD model was established by intracranial inflating (14). All animals were anesthetized with pentobarbital solution $(50 \mathrm{mg} / \mathrm{kg})$ via an intraperitoneal injection; atropine solution $(0.03 \mathrm{mg} / \mathrm{kg})$ was used to decrease secretion of glands. Following anesthesia, rats were fixed on a homeothermic warming blanket linking to an Intelligent Temperature Controller (Taimeng Biological Technology Co., Ltd.) with the temperature probe placed into the anus to maintain temperature at $\sim 38 \pm 1^{\circ} \mathrm{C}$. Skin of calva was prepared. The scalp and the epicranial muscles and periosteum were excised. A 2-mm diameter hole was drilled on the skull at the intersection of sagittal line and the midpoint of two eyes. A 3F Fogarty catheter balloon (Fogarty Arterial Embolectomy Catheter, 3F, Edwards Lifesciences Co.) was put into the epidural space completely through the burr hole. Then, the catheter was gradually inflated to a final volume of $\sim 2,000 \mathrm{ml}$. The femoral artery was catheterized to monitor blood pressure. The femoral vein was catheterized to prepare for fluid administration. An electrocardiogram and electroencephalogram were monitored using the Biological Function Date Acquisition and Monitoring System (Taimeng Biological Technology Co., Ltd.); tracheal intubation was also performed. The criterions of BD were referred to China Adult Brain Death Determination Technology Specifications and USA Adult Brain Death Diagnostics Guide (15). Rats of the BD group had underwent BD which was maintained for $6 \mathrm{~h}$. Sham-operation rats were anesthetized, skull-drilled and intracranial catheterized but without inflating; anesthesia was maintained for 6 h. 4-PBA was administered $300 \mathrm{mg} / \mathrm{kg}$ via an intraperitoneal injection when the $\mathrm{BD}$ model was established; liver specimens were harvested $6 \mathrm{~h}$ after BD.

Exposure of the liver. After $6 \mathrm{~h}$ of $\mathrm{BD}$, the peritoneal cavity was opened. The falciform ligament and bilateral deltoid ligament were moved to carefully expose the liver. The liver was gently moved with a sterile swab and then placed on a piece of sterile gauze. The color and appearance of the liver was analyzed under a fine-light view.

Histology. Following reperfusion, about $0.25 \mathrm{~g}$ liver samples were fixed with $10 \%$ buffered formalin for $24 \mathrm{~h}$ at room temperature ( $\mathrm{pH}=7.2$; cat. no. G2161; Beijing Solarbio Science \& Technology, Co., Ltd.), then put into 75, 80, 85, 90,95 and 100\% alcohol for $1 \mathrm{~h}$ respectively, so as to fully dehydrate the tissues. Following dehydration, the tissues were soaked in 50\% alcohol + 50\% xylene solution for $30 \mathrm{~min}$, and then soaked in $100 \%$ xylene until they became transparent. The transparent samples were soaked in liquid paraffin at $60^{\circ} \mathrm{C}$ twice $(1 \mathrm{~h}$ each) until the paraffin had completely infiltrated. The samples after paraffin immersion were embedded in paraffin wax and cut into 4- $\mu \mathrm{m}$ sections for histological analysis via hematoxylin-eosin staining (H\&E; hematoxylin staining for 5-15 min and eosin staining for 1-3 min; all performed at room temperature). Sections were analyzed under a confocal microscope (magnification, x200; Nikon A1R/A1; Nikon Corporation) and images were obtained. A total of 6 fields of view per section were randomly selected for the assessment of liver damage. Numerical assessment of liver damage was conducted according to the histological criteria for assessment of liver damage.

Western blot analyses. Protein expression of glucose-regulated protein 78 (Grp78), ATF6, PP2A and phosphorylated PP2A (PP2A Y307) were examined by western blotting. Frozen liver tissues were cut into pieces and solubilized in radioimmunoprecipitation assay buffer (cat. no. G2002; Wuhan Servicebio Technology Co., Ltd.) with phenylmethanesulfonyl fluoride $10 \mu \mathrm{l} / \mathrm{ml}$. The turbid liquid was centrifuged for $15 \mathrm{~min}$ at $12,000 \mathrm{x} \mathrm{g}$ at $4^{\circ} \mathrm{C}$. Protein concentration of the supernatant was determined by the bicinchoninic acid kit (cat. no. G2026; Wuhan Servicebio Technology Co., Ltd.). Then, the extracted protein was mixed with $5 \mathrm{X}$ loading buffer containing bromophenol blue as an indicator, which was then heated to $100^{\circ} \mathrm{C}$ for $10 \mathrm{~min} .10 \%$ SDS-PAGE was performed with equal protein quantity each group using a constant voltage of $80 \mathrm{~V}$ in spacer gel and $120 \mathrm{~V}$ in separation gel. After electrophoresis, proteins were transferred to a polyvinylidenedifluoride filter membrane with a constant electric current of $278 \mathrm{~mA}$ in a mixture of ice and water. The membrane was blocked in 5\% nonfat milk for $1 \mathrm{~h}$ at room temperature and incubated overnight at $4^{\circ} \mathrm{C}$ with anti-Grp78 (1:1,000, bs-1219R, Beijing Biosynthesis Biotechnology Co., Ltd., China), anti-ATF6 (1:1,000, bs-1634R, Beijing Biosynthesis Biotechnology Co.,Ltd., China), anti-total PP2A (1:1,000, ab32104, Abcam), anti-PP2A Y307 (1:1,000, AF1756, Beyotime Institute of Biotechnology) and anti- $\beta$-actin (1:3,000, AF0003, Beyotime Institute of Biotechnology). Following washing with TBS-T, the membranes were then incubated for $2 \mathrm{~h}$ in anti-rabbit $\operatorname{IgG}(1: 3,000, \mathrm{~GB} 23303$, Wuhan Goodbio Technology Co. Ltd.) at $37^{\circ} \mathrm{C}$. Finally, the bands were visualized using an enhanced chemiluminescence reagent (cat. no. G2020; Wuhan Servicebio Co., Ltd.). Then, the bands were scanned and analyzed with Image-Pro Plus v6.0 software (Media Cybernetics, Inc.).

Activation of PP2A. The activation of PP2A was detected with a quantitative detection kit (GMS50042.3, Genmed Scientific 
Inc.) by reactive colorimetry. Washing buffer $(3 \mathrm{ml})$ was added to $500 \mathrm{mg}$ liver tissue of each group; following washing they were placed in liquid nitrogen overnight. The next day $500 \mu \mathrm{l}$ lysate buffer was added to each group and fully lysed with vortex oscillation. Then all the lysate were incubated for $30 \mathrm{~min}$ at $4^{\circ} \mathrm{C}$ and centrifuged for $5 \mathrm{~min}$ at $16,000 \mathrm{x}$ g. Protein concentration of each group was detected by the bicinchoninic acid kit (cat. no. G2026; Wuhan Servicebio Technology Co., Ltd.) for later use. According to the protocol, the standard curves were drawn with negative and standard solutions of different concentrations. Then, $20 \mu \mathrm{l}$ protein lysates of each group were taken to measure the background phosphorus concentration, total active phosphorus concentration and non-specific active phosphorus concentration by spectrophotometer (Shanghai CHOIF Co., Ltd.) and the specific phosphorus concentration of each sample was calculated according to the manufacturer's protocol.

Terminal deoxynucleotidyl transferase-mediated 2'-deoxyuridine 5'-triphosphate nick-end labeling (TUNEL) assay. Cell apoptosis of each group was detected by TUNEL assay. Detection was performed with the One Step TUNEL Apoptosis Assay Kit (Beyotime Institute of Biotechnology); 4- $\mu$ m paraffin sections were deparaffinized in xylene (Sinopharm Chemical Reagent Co., Ltd.) three times (10 min each) and rehydrated in alcohol (anhydrous, $95,80,75 \%$ ) and double distilled water successively, $5 \mathrm{~min}$ each. Then, the sections were treated with proteinase $\mathrm{K}$ for $20 \mathrm{~min}$ at room temperature and subsequently incubated at room temperature with a mixture of fluorescent labeling solution and TdT enzyme for $1 \mathrm{~h}$ in a the dark. After washing in PBS and drying, sections were incubated with DNase I for $10 \mathrm{~min}$ in the dark at room temperature. Then the sections were gently shaken to dry, DAPI staining solution was added to the tissue, incubated in dark for $10 \mathrm{~min}$ at room temperature. Finally the sections were washed with PBS for 3 times, 5 min each time, and sealed with anti-fluorescence quenching agent. The fluorescein isothiocyanate-labeled TUNEL-positive cells were imaged using fluorescent microscopy with $488 \mathrm{~nm}$ excitation and $530 \mathrm{~nm}$ emission wavelengths, and DAPI with $364 \mathrm{~nm}$ excitation and $454 \mathrm{~nm}$ emission wavelengths. The cells labeled with green fluorescence were deemed apoptotic cells.

Statistical analysis. Statistical analysis was performed with SPSS for windows version 17.0 (SPSS, Inc.). Continuous variables were presented as the mean \pm standard deviation unless explicitly noted otherwise. Statistical significance between groups was tested by one-way ANOVA with Tukey's post-hoc test. $\mathrm{P}<0.05$ was considered to indicate a statistically significant difference.

\section{Results}

Macroscopic appearance of livers. As presented in Fig. 1, variations in the macroscopic appearance of livers were observed. Livers of the S group were normally red, with a clear edge and smooth surface. BD livers were aubergine in color and the edge of liver was blunt with notable edema. 4-PBA livers had a more pronounced shape and were brighter in color than the BD group, but less so than the $\mathrm{S}$ group.
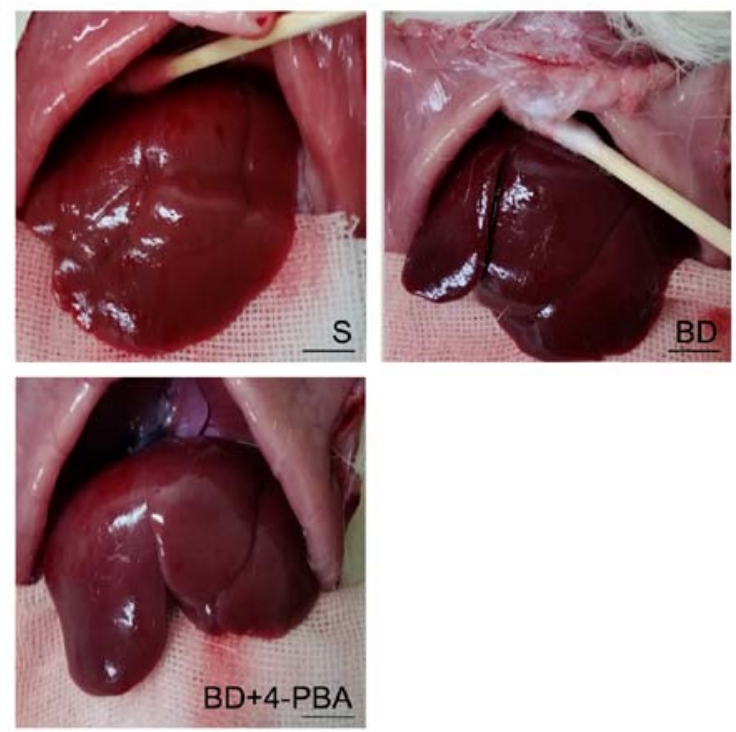

Figure 1. Appearance of the liver. Scale bar $=1 \mathrm{~cm}$. Livers of $\mathrm{S}$ group were red, with a clearly visible edge and a smooth surface. BD livers were aubergine in color, while the edge of liver was blunt with notable edema. 4-PBA livers had a more pronounced shape and were brighter color than the BD group, but less so the S group. 4-PBA, phenylbutyric acid; BD, brain death; S, Sham.
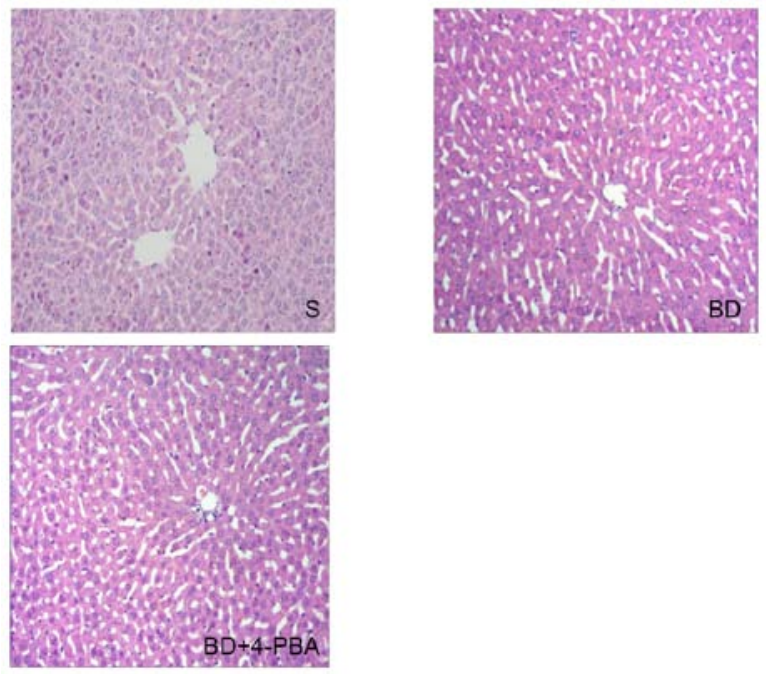

Figure 2. Histological changes of livers (magnification, x200). Livers of S group exhibited normal histology; hepatic sinusoids were seen in an orderly matrix and the hepatic lobule was integrated. While a misaligned and malformed hepatic sinusoid, irregular cell arrangement, a malformed hepatic lobule, and swelled liver cells and apoptosis were observed in the livers of BD group. Treatment with 4-PBA lessened the extent of hepatic injury associated with BD. 4-PBA, phenylbutyric acid; BD, brain death; S, Sham.

Histological changes. Hematoxylin-eosin staining was performed using the liver sections of the three groups, which were then observed under an optical microscope; representative images of analysis were presented in Fig. 2. In the $\mathrm{S}$ group, livers were histologically normal, as depicted by an orderly matrix of the hepatic sinusoid and an integrated hepatic lobule. In the BD group the hepatic sinusoid was misaligned; the hepatic lobule was malformed, while central venous endothelial injury, swelled liver cells and apoptosis were observed. Treatment with 4-PBA lessened the injury of to the hepatic lobule associated with BD. 

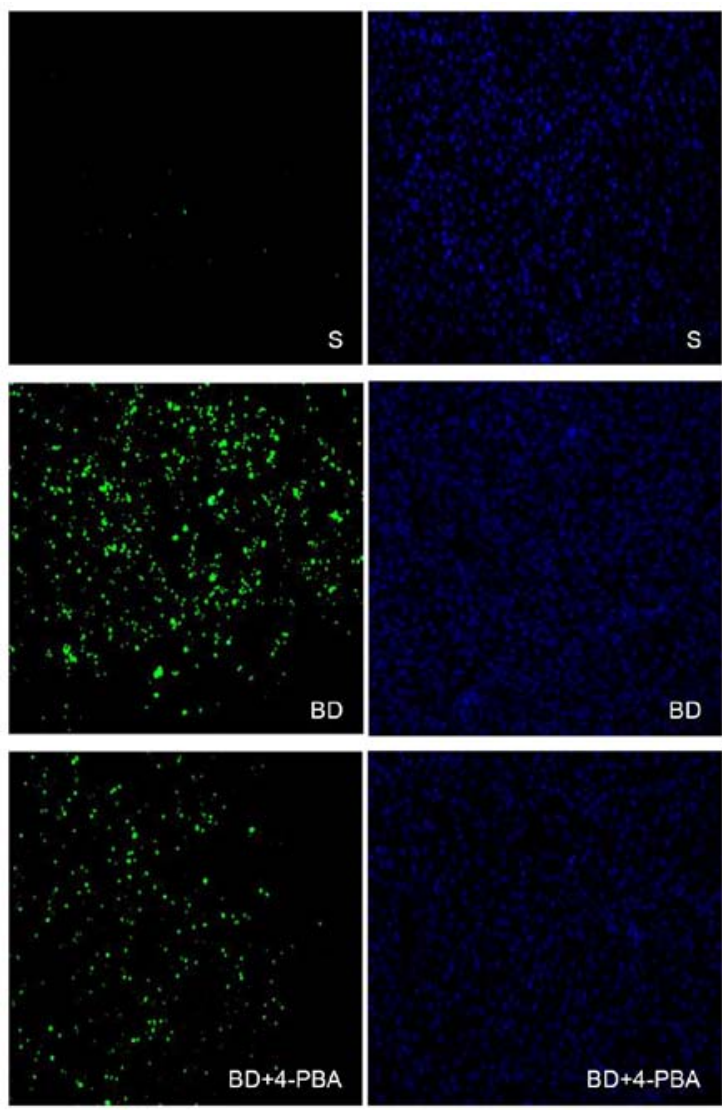

Figure 3. Apoptosis was detected by a TUNEL assay (magnification, x100). Green fluorescence was positive result of TUNEL staining which indicated cell death, while blue fluorescence was positive for DAPI staining, which indicated the total number of cells. The results showed that the apoptosis of $\mathrm{S}$ the group was lower than the BD and 4-PBA groups, while notable differences were also reported between the 4-PBA and BD groups. 4-PBA, phenylbutyric acid; BD, brain death; S, Sham; TUNEL, terminal deoxynucleotidyl transferase-mediated 2'-deoxyuridine 5'-triphosphate nick-end labeling.

BD promotes the apoptosis of liver cells. The extent of liver cell apoptosis was presented in Fig. 3. Liver specimens after TUNEL straining were observed with an inverted fluorescence microscope. Green fluorescence was positive a result of the TUNEL assay, which indicated cell death, while blue fluorescence indicated positive DAPI staining for the total number of cells. The results showed that the apoptosis of the $\mathrm{S}$ group was only $10 \pm 1 \%$, which is significantly lower than the $\mathrm{BD}(80 \pm 2 \%, \mathrm{P}<0.05)$ and 4-PBA $(68 \pm 2 \%, \mathrm{P}<0.05)$ groups, while differences between the 4-PBA and $\mathrm{BD}$ groups were statistically significant $(\mathrm{P}<0.05$; Table I).

$B D$ increases the activation of $P P 2 A$. Activation of $\mathrm{PP} 2 \mathrm{~A}$ was detected via colorimetry. As shown in Fig. 4, compared with the $S$ group $(1.898 \pm 0.337 \mathrm{nmolP} / \mathrm{mg} / \mathrm{min})$, the PP2A activity of the $\mathrm{BD}(4.008 \pm 0.566 \mathrm{nmolP} / \mathrm{mg} / \mathrm{min}, \mathrm{P}=0.005)$ and 4-PBA $(2.874 \pm 0.241 \mathrm{nmolP} / \mathrm{mg} / \mathrm{min}, \mathrm{P}=0.015)$ groups were significantly increased. In addition, PP2A activation in the BD group was significantly higher than in the 4-PBA group $(\mathrm{P}=0.033)$.

BD promotes the expression of Grp78 and ATF6. The expression of Grp78 and ATF6 was detected by western blotting to
Table I. Quantification of TUNEL assay.

\begin{tabular}{lccc}
\hline & $\mathrm{S}(\%)$ & $\mathrm{BD}(\%)$ & $\mathrm{BD}+4-\mathrm{PBA}(\%)$ \\
\hline TUNEL positive & $10 \pm 1$ & $8 \pm 2$ & $68 \pm 2$ \\
DAPI positive & $93 \pm 2$ & $93 \pm 2$ & $92 \pm 1$ \\
\hline
\end{tabular}

4-PBA, phenylbutyric acid; BD, brain death; S, Sham; TUNEL, terminal deoxynucleotidyl transferase-mediated 2'-deoxyuridine 5'-triphosphate nick-end labeling; PBA, phenylbutyric acid; BD, brain death; S, Sham.

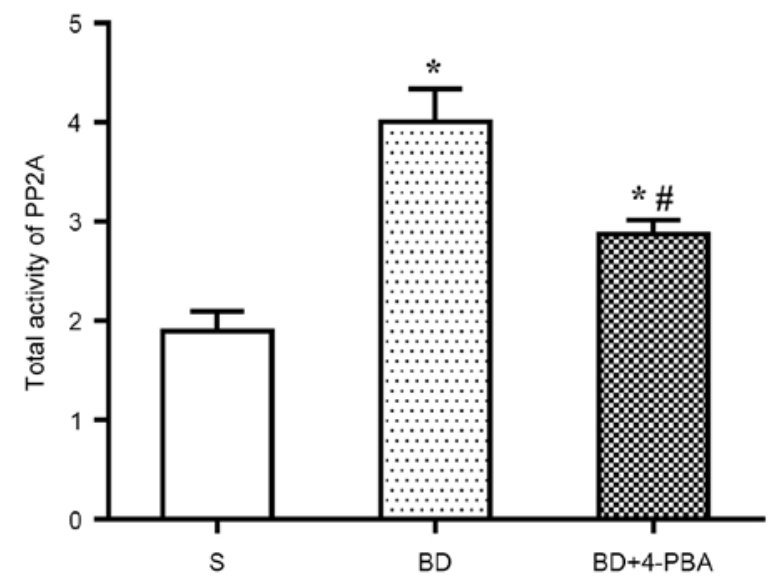

Figure 4. Activation of PP2A as detected by colorimetry. Compared with the $\mathrm{S}$ group, PP2A activity of the BD and 4-PBA groups were significantly increased. Additionally, PP2A activation in the BD group was significantly increased than in the 4 -PBA group. ${ }^{*} \mathrm{P}<0.05$ vs. the $\mathrm{S}$ group. ${ }^{\#} \mathrm{P}<0.05$ vs. the $\mathrm{BD}$ group. 4-PBA, phenylbutyric acid; $\mathrm{BD}$, brain death; $\mathrm{PP} 2 \mathrm{~A}$, protein phosphatase $2 \mathrm{~A} ; \mathrm{S}$, Sham.

assess the activation of ERS (Fig. 5). The results showed that the expression of Grp78 was significantly increased in the BD $(2.792 \pm 0.151, \mathrm{P}<0.001)$ and $4-\mathrm{PBA}(2.011 \pm 0.174, \mathrm{P}=0.003)$ group compared with the $\mathrm{S}$ group $(0.881 \pm 0.014)$. Consistent with the increase Grp78 expression, ATF6 expression was also increased significantly in the BD $(1.287 \pm 0.116, \mathrm{P}<0.01)$ and 4-PBA $(0.961 \pm 0.108, \mathrm{P}=0.014)$ groups than the $\mathrm{S}$ group $(0.692 \pm 0.155)$. The expression of Grp78 and ATF6 after 4-PBAtreatment were significantly lower than in the BD group ( $\mathrm{P}=0.015$ and 0.003 , respectively).

$B D$ suppresses the phosphorylation of $P P 2 A$, which is reversed by4-PBA. Total expression of total $\mathrm{PP} 2 \mathrm{~A}$ and phosphorylated PP2A (PP2A Y307) were detected by western blotting. The results indicated no significant differences in total PP2A between the S and BD $(2.096 \pm 0.101$ vs. 2.197 $\pm 0.109, \mathrm{P}=0.586$; Fig. 6). The expression of PP2A Y307 was significantly decreased after $B D$ than in the $\mathrm{S}$ group $(0.467 \pm 0.066$ vs. $3.780 \pm 0.473, \mathrm{P}=0.002)$, indicating that $\mathrm{BD}$ suppressed the phosphorylation of $\mathrm{PP} 2 \mathrm{~A}$, which promoted the activation of PP2A. In addition, the expression of PP2A Y307 of the 4-PBA $(1.632 \pm 0.222)$ group was significantly higher than the $B D$ group $(\mathrm{P}=0.007)$ but lower than the $\mathrm{S}$ group ( $\mathrm{P}=0.015$; Fig. 6). 

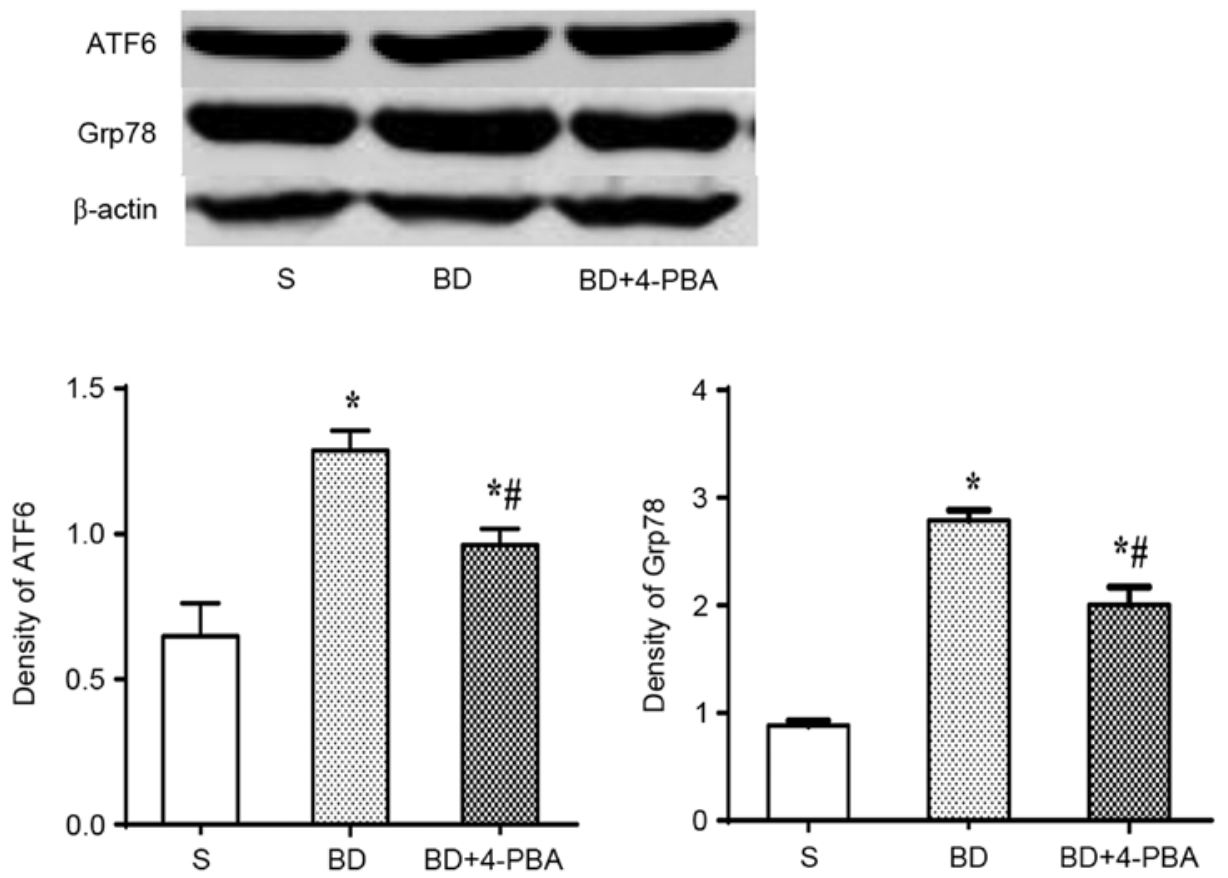

Figure 5. Expression of Grp78 and ATF6 as detected by western blotting. The results showed that the expression of Grp78 was increased in the BD and 4-PBA groups compared with the $\mathrm{S}$ group. Consistent with the increase in Grp78, ATF6 expression was significantly upregulated in the BD and 4-PBA groups than the $\mathrm{S}$ group. Furthermore, the expression levels of Grp78 and ATF6 after 4-PBA treatment were significantly decreased than in the BD group. "P<0.05 vs. the S group, ${ }^{\prime} \mathrm{P}<0.05$ vs. the BD group. 4-PBA, phenylbutyric acid; BD, brain death; ATF6, activating transcription factor 6; Grp78, glucose-regulated protein 78; S, Sham.
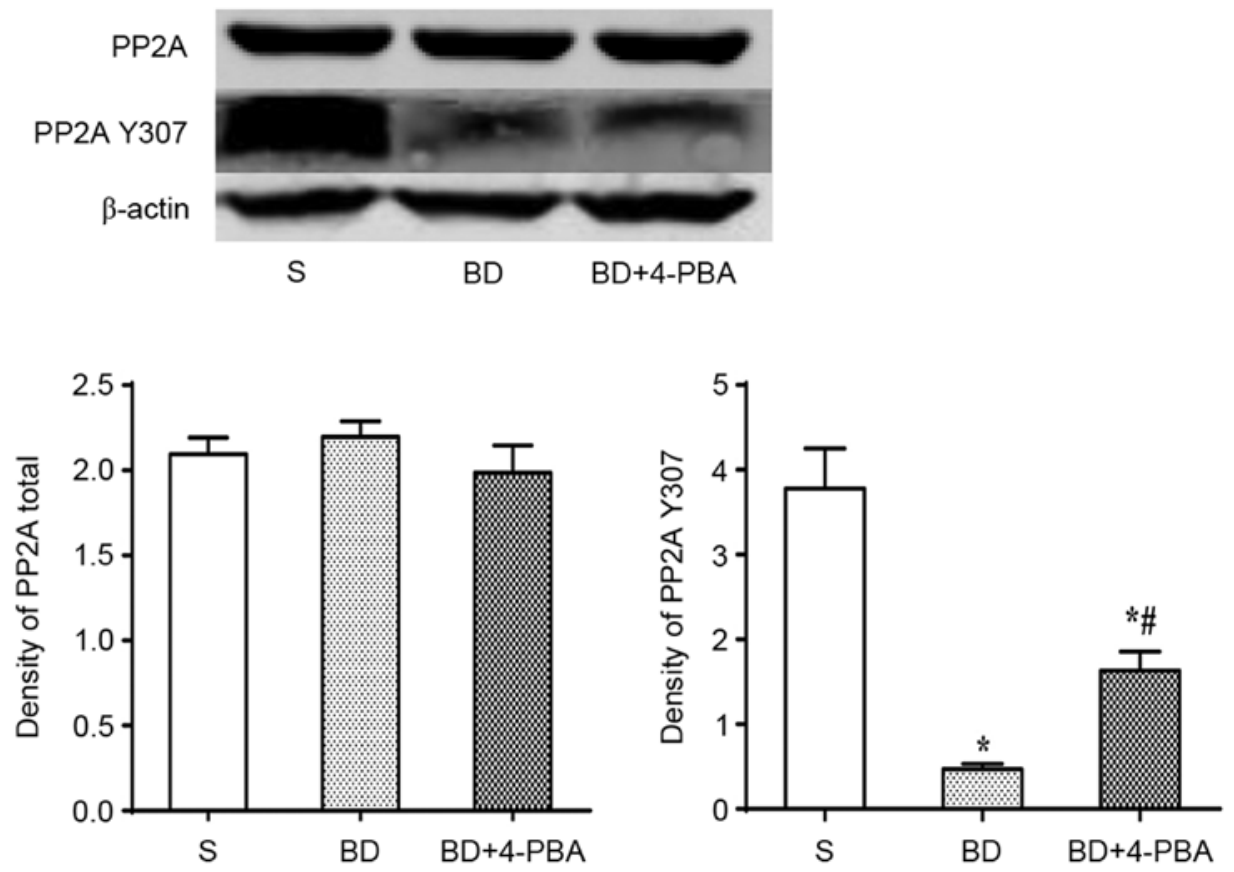

Figure 6. Expression of total PP2A as detected by western blotting. The results showed no significant difference in total PP2A between the S and BD groups. The expression of PP2A Y307 was significantly decreased after BD than in the S group, indicating that BD suppressed the phosphorylation of PP2A which promoted the activation of PP2A. In addition, the expression of PP2A Y307 of the 4-PBA group was higher than the BD group but lower than the S group. ${ }^{\text {"P }}<0.05$ vs. S group, ${ }^{,} \mathrm{P}<0.05$ vs. the BD group. 4-PBA, phenylbutyric acid; BD, brain death; PP2A, protein phosphatase 2A; PP2A Y307, phosphorylated PP2A; S, Sham.

\section{Discussion}

Since its clinical application, LT has saved the lives of thousands of patients with end-stage liver diseases globally.
The majority of donations in China are post mortem. The use of DBD organs has expanded the donor pool effectively, yet $\mathrm{BD}$ has been confirmed to be involved in a series of pathophysiological processes associated with liver damage, 
including hemodynamic instability, inflammatory responses, immunological changes and cytokine-induced liver cell apoptosis (16). A previous study showed that ERS may play a role in BD-induced cell damage, but the underlying mechanisms remain unclear (17). To reveal the possible relationship between ERS and liver damage, a rat BD model was established by gradual intracranial inflating. The present study demonstrated that the expression of Grp78 and ATF6 were increased significantly under conditions of BD. Grp78, also known as immunoglobulin heavy chain binding protein, is a member of the heat shock protein 70 protein family (18). GRP78 is an ER chaperone protein that primarily resides in the lumen of the ER and is the master regulator of the unfolded protein response (UPR) (19), binding to all 3 ERS sensors (PERK, ATF6 and IRE1) and inhibiting their function under normal physiological condition (20). ER stress could increase the expression of Grp78 and promote Grp78 translocation to the cell surface, causing activation of the ERS sensors (21). A previous study showed that Grp78 could inhibit breast cancer cell apoptosis via AKT/mitochondrial pathway (22). Additionally, reducing the expression of Grp78 resulted in the poor prognosis of patients with advanced head cancer (23). ATF6 is one member of the ATF/CREB family and serves as a transmembrane protein of ER (24). It is a membrane-bound transcription factor in ER and regulates many pathophysiological processes including apoptosis (25), pediatric inflammatory bowel disease (26) and odontoblastic differentiation (27). ATF6 is localized at the ER under basal conditions (24). In cells undergoing ERS, ATF6 translocates to the Golgi apparatus and is processed by site 1 protease and site 2 protease releasing ATF6f, which controls the upregulation of select UPR target genes (28). Cleaved ATF6 could also increase the expression of Grp78 (29), and Grp78 could induce apoptosis through the mitochondrial and non-mitochondrial pathway (30). Therefore, ATF6 and Grp78 could be considered as biomarkers of ERS.

PP2A is a major serine/threonine phosphatase in cells. Only two forms have been observed in cells until now. The holoenzyme of PP2A contains a structural A subunit, a regulatory B subunit and a catalytic C subunit (9). The core enzyme is a dimer consisting of an $\mathrm{A}$ subunit and a $\mathrm{C}$ subunit. The $\mathrm{C}$ subunit alone was not found in vivo (9). It has been shown that A subunits regulate PP2A holoenzyme composition, and catalytic activity of PP2A is mainly depend on C subunits (31). B subunits exert a wide variety of effects. Different B subunits have different structures, localization and functions to the PP2A homoenzyme $(32,33)$. A previous study showed that activation of PP2A induces apoptosis by dephosphorylating Bad and Bcl-2 directly (34). In addition, PP2A could also induce apoptosis through the MAPK and AKT/PKB pathways $(35,36)$. Phosphorylation decreased the catalytic activation of PP2A (37). There have been many studies that have revealed that activation of ERS and PP2A may have a synergistic effect on cell damage under different pathological states (38-40). According to a study on neurodegenerative disorders, after rat brain endothelial cells were exposed to okadaic acid, a well-known inhibitor of PP2A, inhibition of PP2A and an increase in ERS markers expression were observed, which suggests that inhibition of PP2A affected ERS (41). Furthermore, research in acute pancreatitis indicated that disulfide stress as a novel type of oxidative stress could activate ERS, and the expression of catalytic subunit of protein phosphatase 2A was increased as well (42). ERS could trigger apoptosis by activating Bim in melanoma cancer cells, while suppression of PP2A could reduce apoptosis induced by ERS, which suggested that ERS may cause cell death via the PP2A pathway (43). In addition, a previous study showed that in liver cells that underwent oxidative stress, the expression of ceramide was increased (44); in an alcoholic liver disease animal model, activation of ERS and upregulation of ceramide, as well as PP2A activation were observed (45). However, further investigation into ERS and PP2A under BD are required.

The present study established a BD model in Sprague-Dawley rats. The apoptosis of liver cells was detected by a TUNEL assay, which suggested that there was a significant increase in apoptosis after BD. The expression of biomarkers of ERS in liver tissues were detected by western blotting. The results showed that expression of Grp78 and ATF6 were increased significantly after BD, indicating that BD could induce ERS in donor livers. Meanwhile, activation of PP2A and the expression of total PP2A and PP2A Y307 were examined. Activation of PP2A significantly increased after BD, but the expression of total PP2A showed no notable differences between the BD and S groups. Furthermore, the expression of PP2A Y307 was decreased significantly after $\mathrm{BD}$, indicating that BD may increase the activation of PP2A by suppressing phosphorylation of PP2A. To investigate the possible relationship between ERS and PP2A, 4-PBA was applied via an intraperitoneal injection when BD was established to suppress the activation of ERS. It was found that 4-PBA decreased the expression of Grp78 and ATF6, while activation of PP2A was reduced. In addition, the expression of PP2A Y307 was increased following 4-PBA treatment. In conclusion, $\mathrm{BD}$ was determined to induce the activation of ERS, subsequently activating PP2A through suppressing its phosphorylation, which leads to liver cell apoptosis, and finally donor liver damage.

\section{Acknowledgements}

Not applicable.

\section{Funding}

The research was supported by the State Key Program of National Natural Science of China (grant no. U1403222); Natural Science Foundation of Hubei province (grant no. 2015CFB208).

\section{Availability of data and materials}

All data generated or analyzed during this study are included in this published article.

\section{Authors' contributions}

$\mathrm{JL}$ and $\mathrm{ZZ}$ performed the research, established the rat brain death model, collected liver specimens, analyzed the data, and wrote the article. YX and YW designed the experiment and helped experiment operations. QY designed the experiments, provided overall guidance, and helped with the manuscript. 


\section{Ethics approval and consent to participate}

The present study was approved by the Wuhan University for Animal Experiment/ABSL-III Laboratory.

\section{Patient consent for publication}

Not applicable.

\section{Competing interests}

The authors declare that they have no competing interests.

\section{References}

1. Wertheim JA, Petrowsky H, Saab S, Kupiec-Weglinski JW and Busuttil RW: Major challenges limiting liver transplantation in the United States. Am J Transplant 11: 1773-1184, 2011

2. Adam R, Karam V, Cailliez V, O Grady JG, Mirza D, Cherqui D, Klempnauer J, Salizzoni M, Pratschke J, Jamieson N, et al: 2018 annual report of the European Liver Transplant Registry (ELTR)-50-year evolution of liver transplantation. Transpl Int 31: 1293-1317, 2018.

3. Belzberg H, Shoemaker WC, Wo CC, Nicholls TP, Dang AB Zelman V, Gruen JP, Berne TV and Demetriades D Hemodynamic and oxygen transport patterns after head trauma and brain death: Implications for management of the organ donor. J Trauma 63: 1032-1042, 2007.

4. Carlessi R, Lemos NE, Dias AL, Oliveira FS, Brondani LA, Canani LH, Bauer AC, Leitão CB and Crispim D: Exendin-4 protects rat islets against loss of viability and function induced by brain death. Mol Cell Endocrinol 412: 239-250, 2015.

5. Cao S, Wang T, Yan B, Lu Y, Zhao Y and Zhang S: Brain death is associated with endoplasmic reticulum stress and apoptosis in rat liver. Transplant Proc 46: 3297-3302, 2014.

6. Salvador-Gallego R, Hoyer MJ and Voeltz GK: SnapShot: Functions of endoplasmic reticulum membrane contact sites Cell 171: 1224.el, 2017.

7. Wang S and Kaufman RJ: The impact of the unfolded protein response on human disease. J Cell Biol 197: 857-867, 2012.

8. Tabas I and Ron D: Integrating the mechanisms of apoptosis induced by endoplasmic reticulum stress. Nat Cell Biol 13 184-190, 2011.

9. Janssens V and Goris J: Protein phosphatase 2A: A highly regulated family of serine/threonine phosphatases implicated in cell growth and signalling. Biochem J 353: 417-439, 2001.

10. Guichard C, Pedruzzi E, Fay M, Marie JC, Braut-Boucher F Daniel F, Grodet A, Gougerot-Pocidalo MA, Chastre E, Kotelevets L, et al: Dihydroxyphenylethanol induces apoptosis by activating serine/threonine protein phosphatase PP2A and promotes the endoplasmic reticulum stress response in human colon carcinoma cells. Carcinogenesis 27: 1812-1827, 2006.

11. Christen V, Treves S, Duong FH and Heim MH: Activation of endoplasmic reticulum stress response by hepatitis viruses up-regulates protein phosphatase 2A. Hepatology 46: 558-565, 2007.

12. Qiu Y, Mao T, Zhang Y, Shao M, You J, Ding Q, Chen Y, Wu D, Xie D, Lin X, et al: A crucial role for RACK1 in the regulation of glucose-stimulated IRElalpha activation in pancreatic beta-cells. Sci Signal 3: ra7, 2010.

13. National Research Council: Guide for the care and use of laboratory animals. 8th edition. The National Academies press, Washington, DC, 2011.

14. Pratschke J, Wilhelm MJ, Kusaka M,Laskowski I and Tilney NL: A model of gradual onset brain death for transplant-associated studies in rats. Transplantation 69: 427-430, 2000.

15. Wijdicks EF: Brain death guidelines explained. Semin Neurol 35 $105-115,2015$

16. Van Der Hoeven JA, Moshage H, Schuurs T, Nijboer M, Van Schilfgaarde R and Ploeg RJ: Brain death induces apoptosis in donor liver of the rat. Transplantation 76: 1150-1154, 2003

17. Cao S, Yan B, Lu Y, Zhang G, Li J, Guo W, Zhao Y and Zhang S: $\mathrm{C} / \mathrm{EBP}$ homologous protein-mediated endoplasmic reticulum stress-related renal apoptosis is involved in rats with brain death. Transplant Proc 47: 354-358, 2015.
18. Rose MD, Misra LM and Vogel JP: KAR2, a karyogamy gene, is the yeast homolog of the mammalian BiP/GRP78 gene. Cell 57: 1211-1221, 1989

19. Gifford JB, Huang W, Zeleniak AE, Hindoyan A, Wu H, Donahue TR and Hill R: Expression of GRP78, master regulator of the unfolded protein response, increases chemoresistance in pancreatic ductal adenocarcinoma. Mol Cancer Ther 15: 1043-1052, 2016

20. Yoshida H, Matsui T, Hosokawa N, Kaufman RJ, Nagata K and Mori K: A time-dependent phase shift in the mammalian unfolded protein response. Dev Cell 4: 265-271, 2003.

21. Lee AS: The ER chaperone and signaling regulator GRP78/BiP as a monitor of endoplasmic reticulum stress. Methods 35: 373-381, 2005.

22. Xie J, Tao ZH, Zhao J, Li T, Wu ZH, Zhang JF, Zhang J and Hu XC: Glucose regulated protein 78 (GRP78) inhibits apoptosis and attentinutes chemosensitivity of gemcitabine in breast cancer cell via AKT/mitochondrial apoptotic pathway. Biochem Biophys Res Commun 474: 612-619, 2016.

23. Kaira K, Toyoda M, Shimizu A, Imai H, Sakakura K, Nikkuni O, Suzuki M, Iijima M, Asao T and Chikamatsu K: Prognostic significance of GRP78/BiP expression in patients with Stage III/IV hypopharyngeal squamous cell carcinoma. Neoplasma 63: 477-783, 2016.

24. Ron D and Walter P: Signal integration in the endoplasmic reticulum unfolded protein response. NatRev Mol Cell Biol 8: 519-529, 2007

25. Morishima N, Nakanishi K and Nakano A: Activating transcription factor-6 (ATF6) mediates apoptosis with reduction of myeloid cell leukemia sequence $1(\mathrm{Mcl}-1)$ protein via induction of WW domain binding protein 1. J Biol Chem 286: 35227-35235, 2011.

26. Negroni A, Prete E, Vitali R, Cesi V, Aloi M, Civitelli F, Cucchiara $S$ and Stronati L: Endoplasmic reticulum stress and unfolded protein response are involved in paediatric inflammatory bowel disease. Dig Liver Dis 46: 788-794, 2014.

27. Kim JW, Choi H, Jeong BC, Oh SH, Hur SW, Lee BN, Kim SH, Nör JE, Koh JT and Hwang YC: Transcriptional factor ATF6 is involved in odontoblastic differentiation. J Dent Res 93: 483-489, 2014.

28. Hetz C, Chevet $\mathrm{E}$ and Harding HP: Targeting the unfolded protein response in disease. Nat Rev Drug Discov 12: 703-719, 2013.

29. Shuda M, Kondoh N, Imazeki N, Tanaka K, Okada T, Mori K, Hada A, Arai M, Wakatsuki T, Matsubara O, et al: Activation of the ATF6, XBP1 and grp78 genes in human hepatocellular carcinoma: A possible involvement of the ER stress pathway in hepatocarcinogenesis. J Hepatol 38: 604-614, 2003.

30. Grkovic S, O'Reilly VC, Han S, Hong M, Baxter RC and Firth SM: IGFBP-3 binds GRP78, stimulates autophagy and promotes the survival of breast cancer cells exposed to adverse microenvironments. Oncogene 32: 2412-2420, 2013.

31. Ruediger R, Fields K and Walter G: Binding specificity of protein phosphatase $2 \mathrm{~A}$ core enzyme for regulatory $\mathrm{B}$ subunits and $\mathrm{T}$ antigens. J Virol 73: 839-842, 1999.

32. Virshup DM and Shenolikar S: From promiscuity to precision: Protein phosphatases get a makeover. Mol Cell 33: 537-545, 2009.

33. Seshacharyulu P, Pandey P, Datta K and Batra SK: Phosphatase: PP2A structural importance, regulation and its aberrant expression in cancer. Cancer Lett 335: 9-18, 2013.

34. Ruvolo PP, Deng X, Ito T, Carr BK and May WS: Ceramide induces $\mathrm{Bcl} 2$ dephosphorylation via a mechanism involving mitochondrial PP2A. J Biol Chem 274: 20296-20300, 1999.

35. Chang H, Lin H, Yi L, Zhu J, Zhou Y, Mi M and Zhang Q: 3,6-Dihydroxyflavone induces apoptosis in leukemia HL-60 cell via reactive oxygen species-mediated $\mathrm{p} 38 \mathrm{MAPK} / \mathrm{JNK}$ pathway. Eur J Pharmacol 648: 31-38, 2010.

36. Liu GP, Wei W, Zhou X, Zhang Y, Shi HH, Yin J, Yao XQ, Peng CX, Hu J, Wang Q, et al: I(2)(PP2A) regulates p53 and Akt correlatively and leads the neurons to abort apoptosis. Neurobiol Aging 33: 254-264, 2012.

37. Takai A and Mieskes G: Inhibitory effect of okadaic acid on the p-nitrophenyl phosphate phosphatase activity of protein phosphatases. Biochem J 275: 233-239, 1991.

38. Malhotra JD and Kaufman RJ: Endoplasmic reticulum stress and oxidative stress: A vicious cycle or a double-edged sword? Antioxid Redox Signal 9: 2277-2293, 2007.

39. Viner RI, Hühmer AF, Bigelow DJ and Schöneich C: The oxidative inactivation of sarcoplasmic reticulum $\mathrm{Ca}(2+)$-ATPase by peroxynitrite. Free Radic Res 24: 243-259, 1996. 
40. Naing C, Mak JW, Wai $\mathrm{N}$ and Maung M: Diabetes and infections-hepatitis $\mathrm{C}$ : Is there type 2 diabetes excess in hepatitis C infection? Curr Diab Rep 13: 428-434, 2013.

41. Plácido AI, Pereira CM, Correira SC, Carvalho C, Oliveira CR and Moreira PI: Phosphatase 2A inhibition affects endoplasmic reticulum and mitochondria homeostasis via cytoskeletal alterations in brain endothelial cells. Mol Neurobiol 54: 154-168, 2017

42. Moreno ML, Escobar J, Izquierdo-Álvarez, Gil A, Pérez S, Pereda J, Zapico I, Vento M, Sabater L, Marina A, et al: Disulfide stress: A novel type of oxidative stress in acute pancreatitis. Free Radic Biol Med 70: 265-277, 2014.

43. Tay KH, Jin L, Tseng HY, Jiang CC, Ye Y, Thorne RF, Liu T, Guo ST, Verrills NM, Hersey P and Zhang XD: Suppression of PP2A is critical for protection of melanoma cells upon endoplasmic reticulum stress. Cell Death Dis 28: e337, 2012.
44. Heinrich M, Wickel M, Schneider-Brachert W, Sandberg C, Gahr J, Schwandner R, Weber T, Saftig P, Peters C, Brunner J, et al: Cathepsin D targeted by acid sphingomyelinase-derived ceramide. EMBO J 18: 5252-5263, 1999.

45. Yang L, Jin GH and Zhou JY: The role of ceramide in the pathogenesis of alcoholic liver disease. Alcohol Alcohol 51: 251-257, 2016.

(i) $(-)$ This work is licensed under a Creative Commons
At NC ND International (CC BY-NC-ND 4.0) License. 